\title{
The design and development of sustainable office building base on the upgraded target in Shanghai
}

\author{
Xiaodan Liang ${ }^{1}$ \\ ${ }^{1}$ School of Civil and Traffic Engineering, Shanghai Urban Construction Vocational College, Yangpu, Shanghai, 200438, China
}

\begin{abstract}
Shanghai, which is the heart of economical centre in china, is developing even faster. The office building is perhaps the most important kind of building type along with the economic development trend. This paper study the design and development of the representative sustainable office building cases in different developing stage in Shanghai from the perspective of architectural design. And conclude the effective sustainable design and management ways by the cases to summarize some references and suggestion of sustainable office. And then the reflecting on the pre-preparation, the controlling of process and the technology selection in the whole design of the sustainable office building in Shanghai.
\end{abstract}

\section{Introduction}

\subsection{The reason to study}

Recent architectural publications are focused on office design and space planning with emphasis on contemporary furniture in office buildings, but mention very little on sustainable concept in the overall aspects of office design and influences. Sustainable development in office design appears to be ignored.

Designers do not really care about this issue, but instead are concerned with the most expensive devices for heating and refrigeration, although there are exceptions where architects and engineers do consider sustainability in construction and design, but rather more on residential buildings and commercial buildings, but a few on office buildings.

For these reasons, the paper will be focus on the study and analysis of the sustainable office building design, in the terms of the research, the innovation planning, construction methods and renewable energy sources used in Shanghai, to assess what level the office building in Shanghai is, how the office building in Shanghai is developing, and what changes will need to be considered.

\subsection{Aims of the paper}

Sustainable office design should not only take much care about the present working environment, but also plan for the further development, including its effect on surrounding human population, the fossil energy used for the following generation etc. This aim of this study is to conclude the development of sustainable office design during about 15 years; and identify a suitable future direction for the office development in Shanghai, which matches the peculiar aspects of (climatelpassive design wayltechnique chosen $\backslash$ management mode). At the same time, it could provide some suggestion for future sustainable office design way in shanghai.

\section{The status of the first sustainable office building completed in Shanghai}

\subsection{Introduction}

It has been over 40 years, when the world petroleum crisis of 1973 occurred. In developed countries, sustainable architecture has passed 3 phases. At the beginning, it was called "energy efficiency buildings", then it became "energy conservation in buildings", which means reducing the energy release in the building. Recently, it has evolved to "energy saving in building". It is to say, the energy has not been saved negatively, but has been actively improving efficiency.

In China, it is called "building energy saving", and it is now at the third of the stated phase. Sustainable development is a recent trend. Responsible architecture must take into account energy and ecology environment. In office building design, green design and sustainable code have become more and more popular and important. The architects' aim is reasonable and effectively using energy.

However, sustainable office design also has some problems, during its development in Shanghai in 2004. Architects pay little attention in the past to the sustainable development of buildings. They are only working to achieve their design targets, ignoring sustainable principles. In the broadest sense, design just meets the client's needs for good office use, but neglects the needs of officers and future generations. It does not consider the

"Corresponding author's e-mail: liangxiaodan@succ.edu.cn 
more protection of the environment, and a rational balance of the use of natural resources.

\section{The sustainable design cases of version 1.0}

\subsection{Introduction}

The first sustainable office (Figure 1), was built in Shanghai by Shanghai Research Institute of Building Sciences (Group) Co., Ltd. in 2004(hereinafter referred to SRIBS), which is the demonstration project to explore the

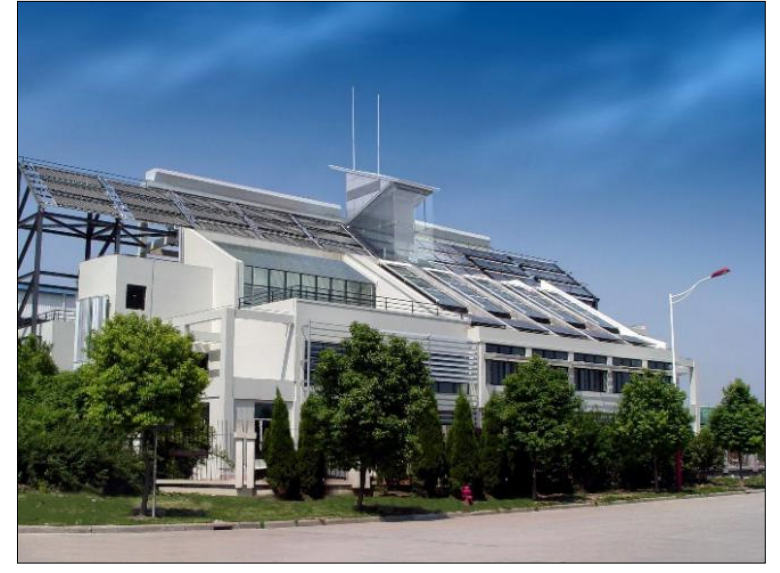

Fig 1. The first sustainable office building

\subsection{Special feature}

\subsubsection{Insulation}

The site is in the hot summer and cold winter area. Considering keeping warm in winter, insulating hot in summer and economic, the designers use four different external wall structure contribute to energy efficiency.

The roof insulation is a key point to be considered, because it has a large area and is a long time endured by direct solarization. The green roof could not only provide a recreation space with a small eco-system, but also insulates the building to reduce cooling and heating energy requirements. The resulting biotope contributes to natural environment and restores the harmony between nature and humans.

\subsubsection{Solar control}

There are six shading technical ways used, including internal and external systems. External solar shading systems are the most efficient way of controlling solar heat gain, because they prevent the sun's rays from reaching the glass. External solar shading can reduce solar heat gain by up to $90 \%$. While internal solar shading systems do eliminate a proportion of solar heat gain by reflecting it back through the glass, their main function is to reduce or eliminate glare. developing mode of the Eco-building. The total energy coasted is only a quarter of energy that is spent in conventional building of the same. Renewable energy is up to $20 \%$ of total energy used in the whole building [1]. This example of sustainable office in Shanghai is a new kind of module in architecture, which has low energy cost and low pollution and also the important part of shanghai sustainable developing strategy. The SRIBS makes the sustainable building design as its Major scientific research mission from 2010. As the following years they set up Sustainable Architecture Evaluation System and research the technology and system of sustainable architecture basing on this project.

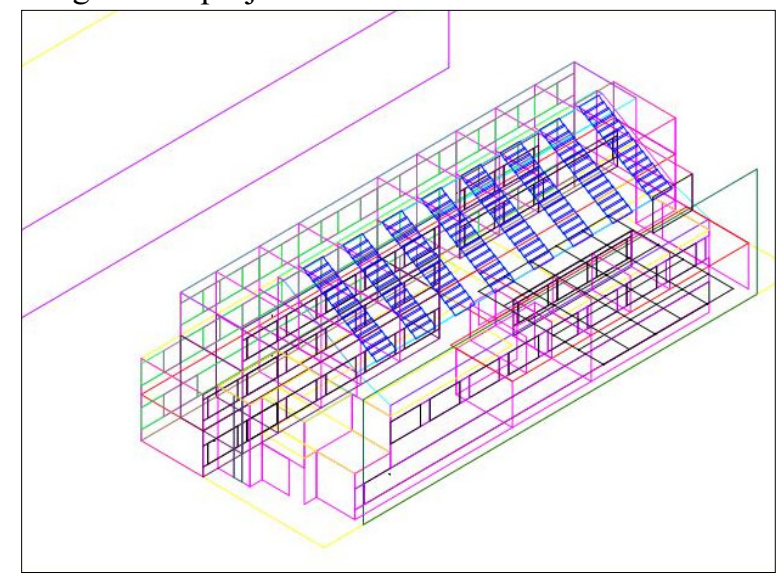

Fig 2. The day lighting analysis

\subsubsection{Ventilation}

The large parts of windows are open able to supply outdoor air, because cross-ventilation (even in airconditioned spaces) lets fresh air in and exhausts hot room air. K. Yeang (1994) said [2]: "Good air movement promotes heat emission from the human body surface and gives a feeling of comfort."

Ventilation stacks extract stale air. Sinusoidal ceilings, which contain ducts inside, provide channels for air distribution. Fans are fitted to the stacks to aid ventilation, when there is little or no wind, or when the temperature is too low to provide an adequate driving force. The new and highly efficient air-condition system could monitor the condition of indoor-air and dispel the humidity. Additionally, computer control windows open automatically as the indoor temperature rises.

\subsubsection{Day lighting}

Ray (2000) said the day lighting is important to re-assess the integration of this abundant resource in building design as a way of creating a more benign living and working environment [3].

The lighting of this building relays on day lighting mostly, excluding very cloudy days, because sunlight could reduce the energy consumption and costs of artificial light.

Daylight also could change and colourful the indoor space. For example, the sunshine irradiates the water on the south side, which can reflect indoor wall, and make it 
lighter, so the office space is not only lighter and more interesting.

And the natural light will vary, depending on the season, time and weather. So, day lighting can also take the outdoor environment into the interior, endowing a space through expansion and openness (Figure 2).

\section{The sustainable office design case of version 3.0}

\subsection{Introduction}

The sustainable office building of version 3.0 named the 10th building (Figure 3), which is in the low carbon

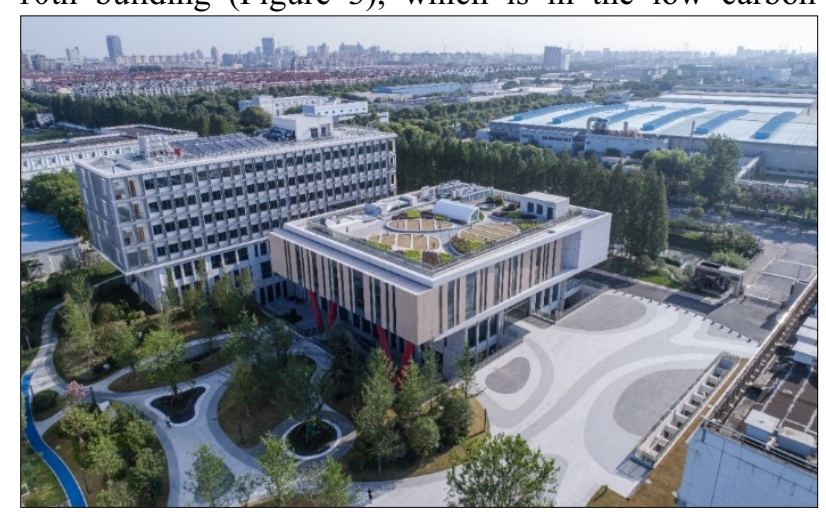

Fig 3. The bird view of the 10th building

\subsection{Special feature}

\subsubsection{The EPC model managed by design institute as the initiating unit}

Some developers, who do not really understand the concept of the sustainable design in architecture, only consider sustainable design as: "an interesting but questionable concept that may have to engage with to obtain planning permission and which is likely to both increase their costs and reduce their profits."'[4] After about 15 years progress of sustainable office design, the architectures find the management mode is another important way to focus: "The better management, the better control, the better sustainable." The innovation of this project is the combination of the EPC management system and the architect responsibility system, to form the new EPC model managed by design institute as the initiating unit.

\subsubsection{The upgrade 3.0 version of sustainable design}

The 1.0 version of sustainable design is the beginning of focusing on low energy, which pay more attention to what kinds of technology to used. As a sustainable building of version 3.0, this project pays more attention to the healthy environment of the building and the links of construction and operation on the basis of the application of sustainable technology. The project applies the technology system of "industrialization, greening and technical park of SRIBS. The site is the same to the project of version 1.0. The project is the first polit program of EPC in Shanghai and also the SRIBS 's newest concept of sustainable building, which is completed in 2019. The case is a comprehensive experiment upgrade from green health v technological and PM.

As the 3rd progress of sustainable office building, the design is not only taking care of the newest technologies and design ways, but also pay more attention to the innovative management model and choose more feasible techniques, for the sustainable concept is beginning from the design, more controlling the progress of construction.

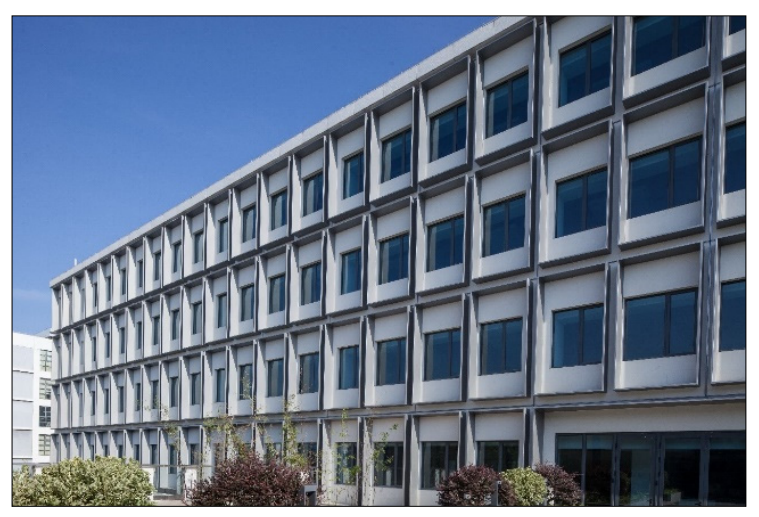

Fig 4. The prefabricated exterior wall

intelligentization", which is a demonstration project of several scientific research subjects. The project won the awards of the National Green Building Three-star rating, the National Healthy Building Three-star rating、 The Green construction site and so on.

\subsubsection{The high-performance of prefabricated exterior wall}

Prefabricated building is a necessary part of the sustainable building system, which contributes greatly to improving the vitality of the building and reducing the consumption of the whole life cycle of the building. After years of development, the prefabricated building is forming a complete system. The prefabricated building forms a closed loop from planning, design, production, assembly, verification, used and other stages.

The building is divided into north and south parts, North and south walls of the north building adopt to precast concrete sandwich insulation exterior wall board + metal shading exterior frame design (Figure 4), which reflects the sense of rhythm and science and technology of sequence. Metal exterior frame is not only the decorative component, but also the shading exterior frame, forming the effect of self-shading, which is in line with the task indicators of the national research project.

We make the experiments, including the air tightness performance test, water tightness performance test, wind pressure resistance test, in-plane deformation performance test and other aspects of omni-directional test to verify the good test performance of joint nodes. The results (Table 1.) of these experiments show the excellent 
performance of the prefabricated exterior wall from those four aspects, which is better than expectation. The results are above or equal to the national design standard.

Table1. Test data and results

\begin{tabular}{llll}
\hline Test item & Design requirement & Test result \\
\hline air tightness & Open area $(\mathrm{m} 3 /(\mathrm{m} . \mathrm{h}))$ & $/$ & $/$ \\
& Test whole $(\mathrm{m} 3 /(\mathrm{m} 2 . \mathrm{h}))$ & $/$ & 0.04 \\
water tightness & Open part $(\mathrm{Pa})$ & $\geq 1000$ & $\geq 1000$ \\
& Fixed part $(\mathrm{Pa})$ & 2.320 & 2.350 \\
Wind pressure resistance & Positive pressure $(\mathrm{kPa})$ & 2.320 & 2.335 \\
& Negative pressure $(\mathrm{kPa})$ & $\geq 1 / 183$ & $\geq 1 / 183$ \\
Room deformation & Angle of interlaminar displacement & $/$ & $/$ \\
Repeating air tightness & Open part $(\mathrm{m} 3 /(\mathrm{m} . \mathrm{h}))$ & $/$ & 0.04 \\
& Whole part $(\mathrm{m} 3 /(\mathrm{m} 2 . \mathrm{h}))$ & $/$ & $/$ \\
$\begin{array}{l}\text { Repeating water } \\
\text { tightness }\end{array}$ & Open part $(\mathrm{Pa})$ & $\geq 1000$ & $\geq 1000$ \\
$\begin{array}{l}\text { Degradation test for } \\
\text { sealant }\end{array}$ & Fixed part $(\mathrm{Pa})$ & $/$ & $/$ \\
& Open part $(\mathrm{Pa})$ & $\geq 1000$ & $\geq 1000$
\end{tabular}

\subsubsection{The suitable passive techniques used}

This sustainable design is more rationale than the version 1.0, which is selecting the suitable passive techniques to the climate of Shanghai. The windows of the whole project are openable for natural ventilation during the transitional season. The multifarious vertical planting is concluding roof gardens、green walls s sinking gardens and so on. The light well、skylight、 light-pipe are used for the natural lighting of underground. The moulding cantilevers and 3D-PC wall provide self-sunshade.

\subsubsection{The suitable renewable system to choose}

The SRIBS sustainable office building of version 1.0 mainly uses the method of sustainable energy sources to save energy. The renewable system links to solar thermal, $\mathrm{PV}$, and geothermal. However, the most renewable energy technologies and practices still in the development and the cost is very expensive, which is a significant obstacle to their widespread use. It is not every company could pay these costs, except the demonstrated office building. The SRIBS sustainable office building of version 3.0 just to chooses the photovoltaic glass of amorphous silicon on balustrade and solar PV on the roof, and reject the GSHP、 solar hot water and so on, which are not suitable for the sit or climate. The renewable technologies of the version 3.0 project selective are more rational and fitting.

\section{Conclusion}

For the paper length, the above cases are just showing the particular aspects. As an unabridged Sustainable building is an organism, so analysing and designing both should consider its sit, planning, solar control, insulation, natural ventilation, indoor climate, building management system, reasonable energy utilized, control noise, eco-lighting system, and so on. In its whole lifecycle, the building is not only considered design investment, but also considered management maintenance and spending to search an optimal point for sustainable design. The guidelines identify the scope of sustainable design; it can be generally and roughly summarized in the following sections:

1) Health and well-being strategies to create healthy indoor environments covering thermal quality, indoor air quality, lighting and acoustic quality.

2) Site and landscaping strategies which enhance the microclimate of the site and minimize the adverse impacts of the building.

3) Energy use emphasizes the importance of energy in sustainable building design and identifies architectural and engineering design strategies to reduce building operating energy use.

4) Materials use presents issues and strategies associated with reducing the amounts of materials used in buildings and the selector of environmentally sound alternatives.

5) Building water use issues and strategies associated with reducing the amounts of potable water used in office buildings. 
6) Waste reduction identifies design strategies to support reduce construction waste and support occupant waste reduction and recycling initiatives.

7) The design management control like the EPC model managed by design institute is a good way to reducing the cost, which is the most important part of the value system.

8) Industrial construction is a new construction mode. The architect will lead the design integration and improve the level of systematic construction technology through the whole process from design to implementation, which is an efficient solution to achieve green environmental protection, advanced technology, sustainable economic.

\section{References}

1. Shanghai green building council. (2012). Shanghai Ecological Office Demonstration Building Project. https://www.shgbc.org/lsjz/n4/n35/u1ai5169.html

2. Yeang, K. (1994) Bioclimatic skyscrapers. Artemis, London.

3. Ray, A. (2000) Sustainable architecture in Japan: The green building of Nikken Sekkei. Wiley-Academy, Chichester.

4. Green, J. (2005). Green Value Green Buildings, Growing Assets Lecture. http://www.Yorkshireuniversities.ac.uk/docs/JimGre en.ppt 